\title{
Spiro-fused carbohydrate oxazoline ligands: Synthesis and application as enantio-discrimination agents in asymmetric allylic alkylation
}

\author{
Jochen Kraft ${ }^{1}$, Martin Golkowski ${ }^{2}$ and Thomas Ziegler ${ }^{* 1}$
}

\author{
Full Research Paper \\ Address: \\ ${ }^{1}$ Institute of Organic Chemistry, University of Tuebingen, Auf der \\ Morgenstelle 18, 72076 Tuebingen, Germany and ${ }^{2}$ Department of \\ Pharmacology, University of Washington, 1959 NE Pacific St, Box \\ 357280, Seattle, WA 98195, USA \\ Email: \\ Thomas Ziegler* - thomas.ziegler@uni-tuebingen.de \\ * Corresponding author \\ Keywords: \\ asymmetric catalysis; carbohydrates; oxazolines; palladium; spiro \\ compounds \\ Beilstein J. Org. Chem. 2016, 12, 166-171. \\ doi:10.3762/bjoc. 12.18 \\ Received: 17 November 2015 \\ Accepted: 18 January 2016 \\ Published: 29 January 2016 \\ Associate Editor: M. Rueping \\ (c) 2016 Kraft et al; licensee Beilstein-Institut. \\ License and terms: see end of document.
}

\begin{abstract}
In the present work, we describe a convenient synthesis of spiro-fused D-fructo- and D-psico-configurated oxazoline ligands and their application in asymmetric catalysis. The ligands were synthesized from readily available 3,4,5-tri- $O$-benzyl-1,2- $O$-isopropylidene- $\beta$-D-fructopyranose and 3,4,5-tri- $O$-benzyl-1,2- $O$-isopropylidene- $\beta$-D-psicopyranose, respectively. The latter compounds were partially deprotected under acidic conditions followed by condensation with thiocyanic acid to give an anomeric mixture of the corresponding 1,3-oxazolidine-2-thiones. The anomeric 1,3-oxazolidine-2-thiones were separated after successive benzylation, fully characterized and subjected to palladium catalyzed Suzuki-Miyaura coupling with 2-pyridineboronic acid $N$-phenyldiethanolamine ester to give the corresponding 2-pyridyl spiro-oxazoline (PyOx) ligands. The spiro-oxazoline ligands showed high asymmetric induction (up to $93 \%$ ee) when applied as chiral ligands in palladium-catalyzed allylic alkylation of 1,3-diphenylallyl acetate with dimethyl malonate. The D-fructo-PyOx ligand provided mainly the $(R)$-enantiomer while the $\mathrm{D}$-psico-configurated ligand gave the $(S)$-enantiomer with a lower enantiomeric excess.
\end{abstract}

\section{Introduction}

The design of new chiral ligands for stereo-differentiating metal catalysts that enable asymmetric syntheses is still a highly active field of research in organic chemistry, for there is a continuously growing demand for enantiomeric pure building blocks for pharmaceuticals, agrochemicals or flavors. Carbohydrates are inexpensive and easy to obtain enantiomerically pure natural products and therefore, nearly ideal starting materials for ex-chiral pool syntheses. In addition, carbohydrates have significantly gained attention as ligands for metal complexes that enable asymmetric catalysis over the past decades, and an array of highly efficient privileged ligands for metal-catalyzed enantioselective syntheses have been derived from carbo- 
hydrates so far [1-6]. However, the enantioselective construction of $\mathrm{C}-\mathrm{C}$ bonds, especially of tertiary carbon stereocenters, remains an ongoing challenge. Over the last decades though, transition metal-catalyzed reactions like the asymmetric allylic alkylation (Tsuji-Trost reaction) have evolved into one of the more powerful tools for synthesizing such tertiary stereocenters $[7,8]$. As a benchmark test for selectivity, the palladium-catalyzed asymmetric addition of dimethyl malonate to $1,3-$ diphenylallyl acetate was often used in the literature for testing the scope of carbohydrate derived ligands for this purpose [9-13]. For instance, Kunz and Gläser have demonstrated the stereo-differentiating potential of carbohydrate ligands in this type of reaction where their gluco-PHOX ligand, derived from glucosamine, resulted in a high enantiomeric excess of up to $98 \%$ [14].

Recently, Vidal et al. reported on a spiro-bis(isooxazoline) ligand A (Figure 1) [15] prepared via 1,3-dipolar cycloaddition of 2,6-pyridinedicarbonitrile $N, N$-dioxide to acetyl protected exo-glucal. The performance of ligand $\mathbf{A}$ in asymmetric catalysis was then tested in the palladium-catalyzed allylic addition of dimethyl malonate to 1,3-diphenylallyl acetate which, however, afforded the desired allylic substitution product only in traces. The authors attributed the inefficiency of ligand $\mathbf{A}$ to the cleavage of the spiro moiety resulting in the formation of thermodynamically more stable aromatic isoxazole B (Figure 1).

As part of our ongoing research program towards the design of carbohydrate derived ligands for metal-catalyzed asymmetric syntheses [16] we recently described the preparation of spirofused oxazoline ligands of type $\mathbf{C}$ from D-fructose [17]. We could demonstrate that our oxazoline ligands, in contrast to $\mathbf{A}$, were able to form air and moisture-stable palladium complexes of type $\mathbf{D}$ upon reaction with $\mathrm{Pd}(\operatorname{cod}) \mathrm{Cl}_{2}$ (Figure 1). Single crystal X-ray diffraction of these Pd complexes revealed some interesting structural features in terms of ligand-metal bite angles and shielding of the palladium center by the carbohydrate scaffold from one specific side [17]. For example, we concluded from the crystallographic data that the orientation of the OBn group at C-3 in D could have a major impact on the "shielded" side of the metal center and thus, also on the stereoselectivity of the palladium-catalyzed allylic addition of dimethyl malonate to 1,3-diphenylallyl acetate. Encouraged by these aspects and in order to further our investigations in asymmetric catalysis with spiro-fused oxazoline ligands, we devised a new convenient synthetic strategy. Herein we present a new straightforward synthesis of spiro-fused D-fructo- and D-psicoconfigurated $\mathrm{PyOx}$ ligands and their application in palladiumcatalyzed asymmetric alkylation.

\section{Results and Discussion}

We started our synthesis from readily available 3,4,5-tri- $O$ benzyl-1,2-O-isopropylidene- $\beta$-D-fructopyranose (1) [18] and 3,4,5-tri- $O$-benzyl-1,2- $O$-isopropylidene- $\beta$-D-psicopyranose (2) [19], respectively (Scheme 1). Deprotection of the isopropylidene group under acidic conditions gave the corresponding diols 3 [20] and 4 as anomeric mixtures. Condensation of the latter with thiocyanic acid in a Ritter-type reaction according to a slightly modified procedure described by Tatibouët et al. [21] gave an anomeric mixture of 1,3-oxazolidin-2-thiones 5 and $\mathbf{6}$, respectively. The anomers of 5 and $\mathbf{6}$ could not be separated by standard column chromatography though. Thiocarbamate $\mathbf{5}$ was previously mentioned in the literature [21], but due to the fast anomerisation and the relative instability of 1,3-oxazolidin-2thiones it was never characterized. However, in our hands, anomers could easily be separated by chromatography after benzylation of 5 and $\mathbf{6}$ with $\mathrm{BnBr}$ and $\mathrm{NaH}$ to give the corresponding benzylated sulfanyloxazolines $\mathbf{7}$ and $\mathbf{8}$ which were air and moisture stable (see Supporting Information File 1 for full experimental details). Nevertheless, it should be noted that these

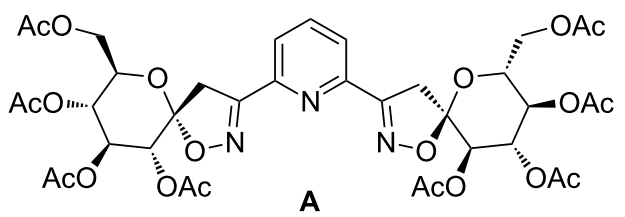

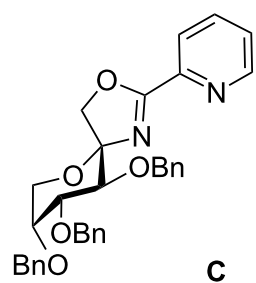

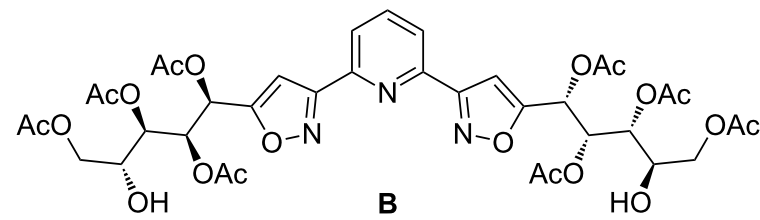

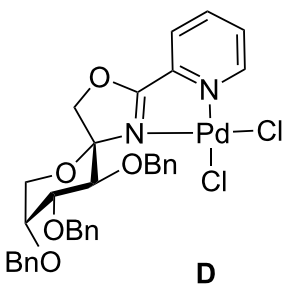

Figure 1: Pd-catalyzed cleavage of spiro-bis(isooxazoline) ligand $\mathbf{A}$ to isoxazole $\mathbf{B}$ and $\mathbf{P d}$-complex $\mathbf{D}$ prepared from spiro-oxazoline $\mathbf{C}$. 


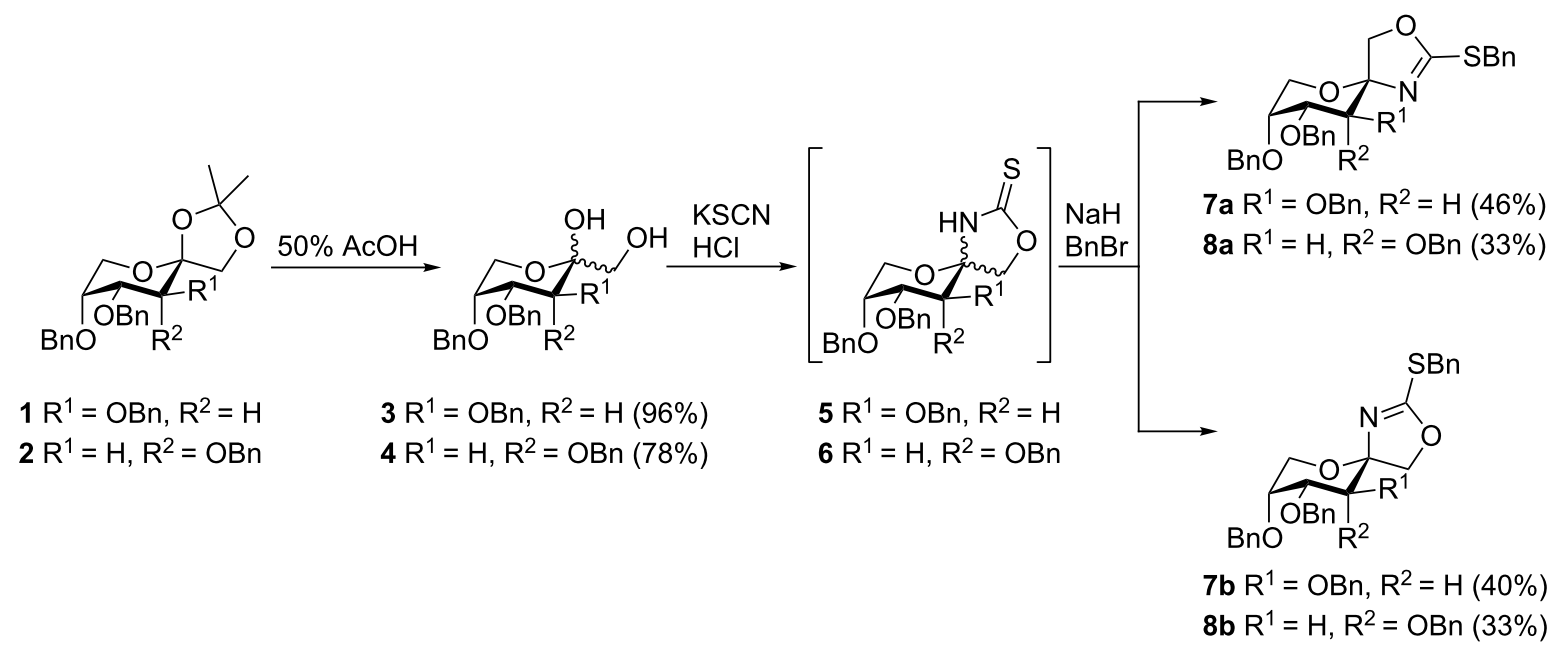

Scheme 1: Synthesis of 2-benzylsulfanyl-1,3-oxazolines 7 and 8.

compounds slowly start to decompose after 2 weeks at $-28{ }^{\circ} \mathrm{C}$ under an atmosphere of nitrogen.

Next, benzylsulfanyloxazolines 7 and $\mathbf{8}$ were subjected to copper-assisted palladium-catalyzed Suzuki-Miyaura-type cross coupling with commercially available 2-pyridineboronic acid $N$-phenyldiethanolamine ester $\mathbf{1 1}$ as boron source (Scheme 2) [22-24]. 2-Pyridineboronic acid 11 was chosen due to its increased nucleophilicity compared to other boron sources like pinacol boronic esters or MIDA boronates [25,26]. The cross coupling proceeded smoothly in THF and gave ligands 9 and $\mathbf{1 0}$ in good yields (Scheme 2). It is noteworthy that the low yield $(32 \%)$ of $10 \mathrm{a}$ is due to the instability of its spiro-fused oxazoline moiety during chromatography on silica gel but not to any unwanted side reactions during the cross coupling. Even small traces of $\mathrm{HCl}$ usually present in $\mathrm{CDCl}_{3}$ as impurity resulted in full decomposition of $\mathbf{1 0 a}$ in seconds.

With ligands 9 and $\mathbf{1 0}$ in hand, we moved on to the application in asymmetric catalysis. As a model system, the Pd-catalyzed allylic alkylation of dimethyl malonate (13) to rac-1,3diphenylallyl acetate (12) was chosen (Scheme 3 ). As mentioned above, this reaction was often used as a benchmark for new chiral ligands and examined in great detail [9-14,27,28].

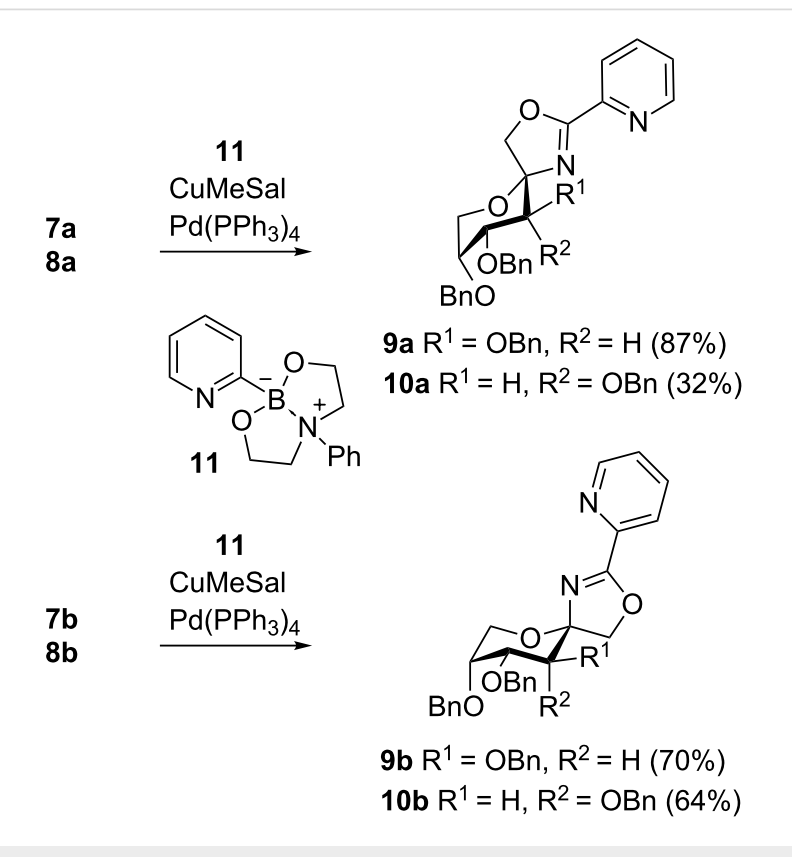

Scheme 2: Pd-catalyzed cross coupling of benzylsulfanyloxazolines 7 and 8 .

In all cases investigated here, the alkylated product 14 was isolated after purification by chromatography and its enantiomeric excess was determined via chiral HPLC using a Reprosil chiral- 
NR column. The absolute configuration was assigned by comparison of the optical rotation values with literature data [29] which are based on the chemical correlation method leading to $(+)-(S)$-2-phenylsuccinate [30] and by X-ray structure determination of $(R, E)$-3,5-diphenylpent-4-enyl camphor-10-sulfonate [31]. Thus, a positive optical rotation value refers to the $(R)$-enantiomer, whereas a negative value belongs to the $(S)$-enantiomer. In addition, the absolute configuration was independently determined by ${ }^{1} \mathrm{H}$ NMR in the presence of the optically active NMR shift reagent $(+)-E u(h f c)_{3}$ [29]. All synthesized ligands were active precatalysts for the allylic substitution, as can be seen in Table 1.

\begin{tabular}{|c|c|c|c|c|}
\hline Entry & Ligand & Solvent & Yielda $^{a}$ & $e e^{b}$ \\
\hline 1 & $9 a$ & $\mathrm{CH}_{2} \mathrm{Cl}_{2}$ & $74 \%$ & $67 \%(R)$ \\
\hline 2 & $9 b$ & $\mathrm{CH}_{2} \mathrm{Cl}_{2}$ & $80 \%$ & $9 \%(R)$ \\
\hline 3 & $9 a$ & $\mathrm{MePh}$ & $68 \%$ & $76 \%(R)$ \\
\hline 4 & $9 a$ & $\mathrm{MeCN}$ & $80 \%$ & $59 \%(R)$ \\
\hline $5^{c}$ & $9 a$ & $\mathrm{CH}_{2} \mathrm{Cl}_{2}$ & $80 \%$ & $71 \%(R)$ \\
\hline $6^{c}$ & $9 a$ & $\mathrm{MePh}$ & $62 \%$ & $88 \%(R)$ \\
\hline $7^{d}$ & $9 a$ & $\mathrm{MePh}$ & $43 \%$ & $93 \%(R)$ \\
\hline 8 & $10 a$ & $\mathrm{MePh}$ & traces & n.d. \\
\hline 9 & $10 a$ & $\mathrm{CH}_{2} \mathrm{Cl}_{2}$ & traces & n.d. \\
\hline $10^{e}$ & $10 a$ & $\mathrm{Cl}\left(\mathrm{CH}_{2}\right)_{2} \mathrm{Cl}$ & $43 \%$ & $59 \%(S)$ \\
\hline 11 & $10 b$ & $\mathrm{MePh}$ & $56 \%$ & $9 \%(S)$ \\
\hline
\end{tabular}

alsolated yield after chromatography. ${ }^{\text {b}}$ Determined by chiral HPLC. ${ }^{\mathrm{c}} T=0{ }^{\circ} \mathrm{C} .{ }^{\mathrm{d}} T=-20^{\circ} \mathrm{C}$. ${ }^{\mathrm{e}} T=50^{\circ} \mathrm{C}$.

The asymmetric allylic alkylation was carried out in the presence of $5 \mathrm{~mol} \%\left[\mathrm{PdCl}\left(\mathrm{C}_{3} \mathrm{H}_{5}\right)\right]_{2}$ and $11 \mathrm{~mol} \%$ chiral ligands 9 and 10, respectively. The D-fructo-configurated ligands $9 \mathrm{a}$ and 9b showed preparative yields for $(R)-\mathbf{1 4}$ in the range of 74-80\% (Table 1, entries 1 and 2). The $\alpha$-anomer 9a showed a significant higher selectivity $(67 \%$ ee) than the $\beta$-anomer $9 \mathbf{b}(9 \%$ ee $)$. In order to investigate the solvent and temperature effects of the reaction we conducted further studies with the more selective ligand 9a. While the reaction proceeded smoothly in all tested solvents, the enantiomeric excess increased in toluene $(76 \%$ ee, Table 1, entry 3), whereas acetonitrile had a negative effect on selectivity (Table 1, entry 4). Lowering the temperature increased the selectivity of the reaction as well (Table 1 , entries $5-7)$. Conducting the reaction at a temperature of $-20{ }^{\circ} \mathrm{C}$ yielded $(R)-\mathbf{1 4}$ with an enantiomeric excess of $93 \%$. Surprisingly, when the D-psico-configurated ligand 10a was used in toluene or methylene chloride under conditions identical to those used with ligand $\mathbf{9 a}$, only traces of the alkylated product $\mathbf{1 4}$ could be obtained. To our delight, however, ligand 10a was active in 1,2-dichloroethane at $50^{\circ} \mathrm{C}$ and gave the opposite enantiomer $(S)-\mathbf{1 4}$ with an enantiomeric excess of $59 \%$ (Table 1 , entry 10 ). Similar to ligand $\mathbf{9 b}$, the $\beta$-configurated D-psicoligand 10b leads to a somewhat lower enantiomeric excess of (S)-14 of 9\% (Table 1, entry 11).

The stereoselectivity of the Pd-catalyzed allylic substitution can be explained via a model for the proposed transition state (Scheme 4). As a consequence of the spiro-fused carbohydrate moiety at the oxazoline ring, exo $(\mathbf{1 5 x}$ and $\mathbf{1 7 x})$ and endo $(\mathbf{1 5 n}$ and 17n) diastereomers of the palladium complexes can be distinguished. It is also reasonable to assume that exo/endo isomers 15 and 17 undergo fast allyl rotation via a $\eta^{3}-\eta^{1}-\eta^{3}$ isomerization mechanism and thus, exist in a dynamic equilibrium which is approximately ten to hundred times faster than alkylation [7]. Therefore, four reaction pathways are possible, but only two lead to the observed stereoselectivties. We assume, that the nucleophilic attack occurs at the allyl terminus trans to the oxazoline ring, which is in accordance with previously reported findings in allylic substitution using PyOx ligands $[32,33]$. If the nucleophile attacks from the $(\mathrm{Si})$-face in the fructo-configurated complex $\mathbf{1 5 n}$ product 14 must have the $(S)$ configuration which is, however, contrary to the observed steroselectivity. Therefore, we suggest $\mathbf{1 5 x}$ to be the preferred isomer for attack by the nucleophile from the $(R e)$-face which leads to the $\eta^{2}$-complex 16 with $(R)$-configuration.

In the case of D-psico-ligand 10a, the $(S)$-enantiomer was found to be the major enantiomer. That leads to the assumption that the endo complex $17 \mathbf{n}$ is the predominant species attacked by the nucleophile from the $(\mathrm{Si})$-face which results in $\eta^{2}$-complex 18 exhibiting $(S)$-configuration. Although the exo complexes are assumed to be thermodynamically more stable than the endo isomers, complex $\mathbf{1 7} \mathbf{x}$ is disfavoured, because of the steric repulsion of the phenyl group in the allylic substrate and the OBn group at C-3 of the D-psicose moiety. This assumption also explains our observation, that the D-psico-configurated ligand 10a requires higher temperatures for formation of the endo complex $17 \mathbf{n}$ and thus, results in a slower reaction rate and in a lower enantioselectivity compared to ligand $\mathbf{9 a}$.

\section{Conclusion}

In summary, we have synthesized four spiro-fused carbohydrate ligands in the D-fructo- and D-psico-series via a straightforward synthetic route. The key steps in our synthesis were a Ritter type condensation reaction of partially benzyl-protected D-fructose and D-psicose derivatives with thiocyanic acid to afford the corresponding 1,3-oxazolidine-2-thiones, and the cross coupling of the latter under modified Suzuki-Miyaura conditions. The prepared ligands were shown to be active precatalysts for the asymmetric allylic alkylation of 1,3diphenylallyl acetate with dimethyl malonate. The D-fructoconfigurated ligands provided the $(R)$-enantiomer with up to 


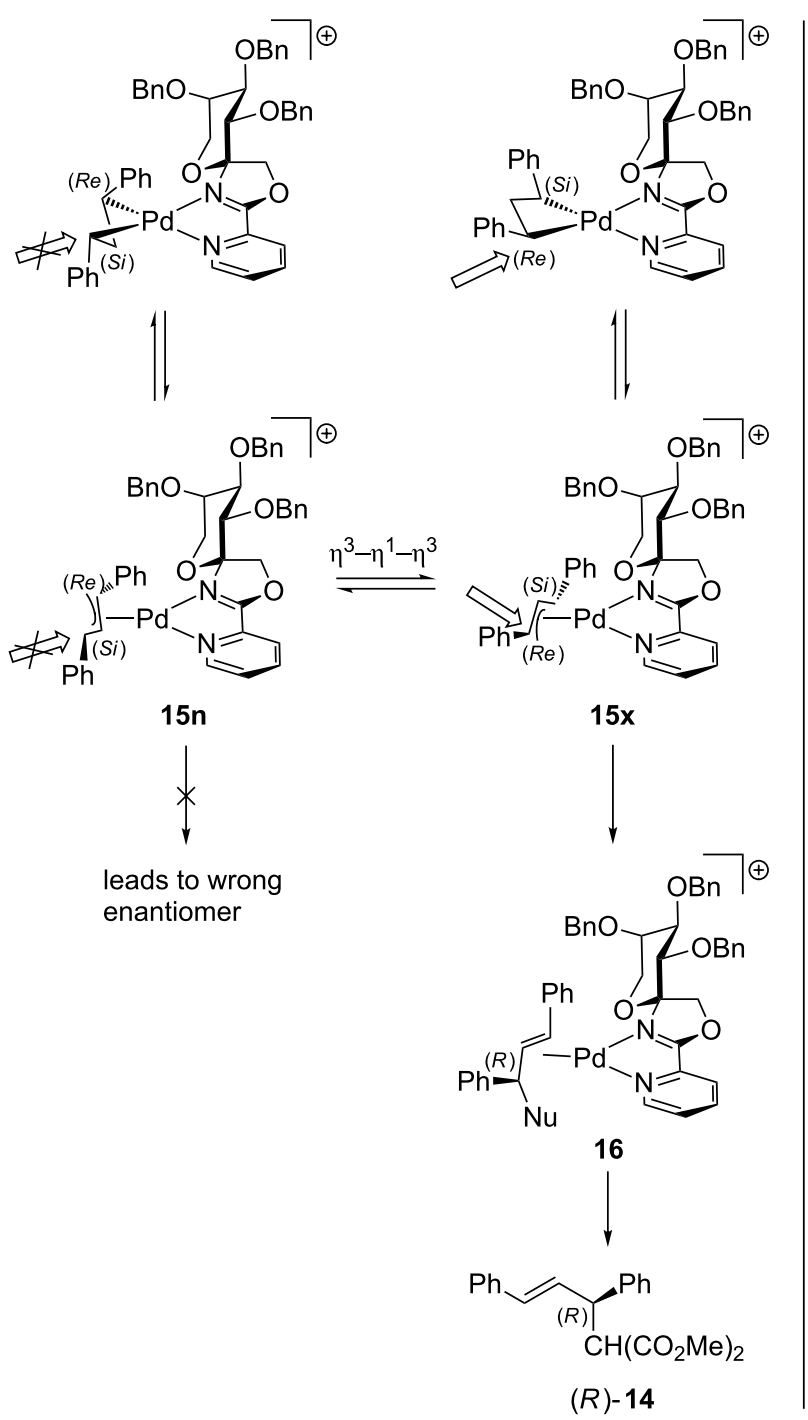

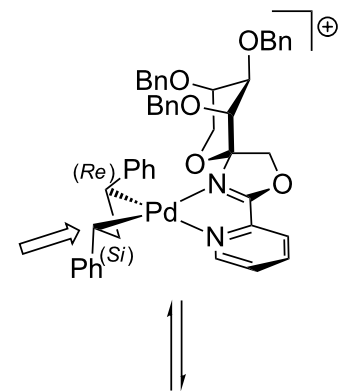
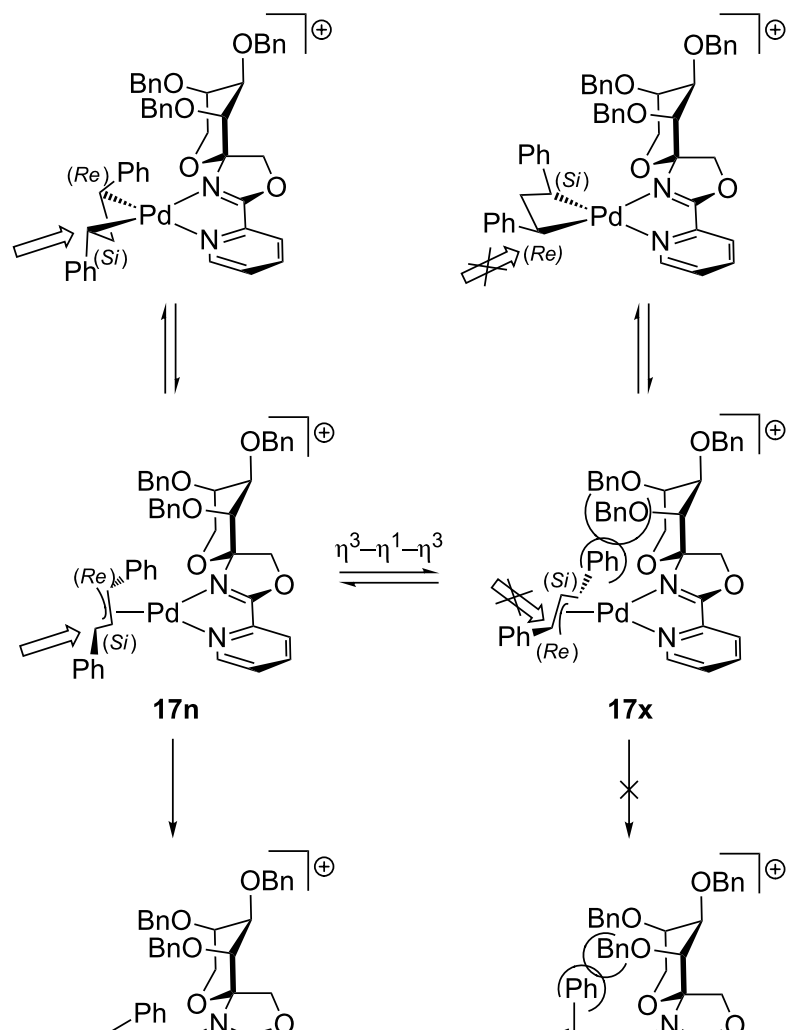

$\mathrm{Nu}$

$\mathrm{Ph}$

d $-\mathrm{N}$<smiles>CN=C(C)C1=NCCN=C1C</smiles>

18

$\left(\mathrm{MeO}_{2} \mathrm{C}\right)_{2} \mathrm{HC}^{(R)} \mathrm{Ph}$<smiles>[Y][V]</smiles>

$\downarrow$

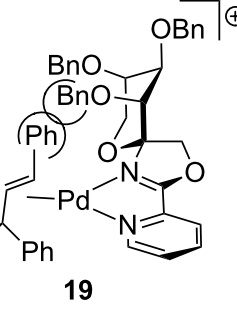

19<smiles>COC(C(C)C)[C@H](/C=C/c1ccccc1)c1ccccc1</smiles>

(S)-14

Scheme 4: Proposed transition state of allylic substitution.

93\% ee, whereas the D-psico-configurated ligands gave the (S)enantiomer in a somewhat lower selectivity (up to $59 \%$ ee). The stereochemical outcome of the reaction could be explained by a proposed transition state of the allylic substitution. Further insights into the reaction mechanism of the allylic substitution using similar PyOx ligands are currently under investigation and will be published elsewhere.

\section{Supporting Information}

\section{Supporting Information File 1}

Experimental procedures, analytical data and copies of NMR spectra.

[http://www.beilstein-journals.org/bjoc/content/ supplementary/1860-5397-12-18-S1.pdf]

\section{Acknowledgements}

Financial support of this work by the Deutsche Forschungsgemeinschaft (DFG) is gratefully acknowledged. We also thank Dr. Dorothee Wistuba and her team for recording the mass spectra, Dr. Markus Kramer and his team for measuring the NMR spectra, Petra Krüger for performing the elemental analyses, Dr. Jochen Neumaier for the help with HPLC analysis and Dr. Gregor Lemanski for helpful discussions.

\section{References}

1. Boysen, M. M. K., Ed. Carbohydrates - Tools for Stereoselective Synthesis; Wiley-VCH: Weinheim, Germany, 2013. doi:10.1002/9783527654543

2. Lehnert, T.; Özüduru, G.; Gruel, H.; Albrecht, F.; Telligmann, S. M.; Boysen, M. M. K. Synthesis 2011, 2685-2708. doi:10.1055/s-0030-1260143 
3. Benessere, V.; Del Litto, R.; De Roma, A.; Ruffo, F. Coord. Chem. Rev. 2010, 254, 390-401. doi:10.1016/j.ccr.2009.05.001

4. Steinborn, D.; Junicke, H. Chem. Rev. 2000, 100, 4283-4317. doi:10.1021/cr9903050

5. Diéguez, M.; Pàmies, O.; Claver, C. Chem. Rev. 2004, 104, 3189-3215. doi:10.1021/cr0306889

6. Castillión, S.; Claver, C.; Díaz, Y. Chem. Soc. Rev. 2005, 34, 702-713. doi:10.1039/b400361f

7. Trost, B. M.; Van Vranken, D. L. Chem. Rev. 1996, 96, 395-422. doi:10.1021/cr9409804

8. Trost, B. M.; Crawley, M. L. Chem. Rev. 2003, 103, 2921-2943. doi:10.1021/cr020027w

9. Diéguez, M.; Jansat, S.; Gomez, M.; Ruiz, A.; Muller, G.; Claver, C. Chem. Commun. 2001, 1132-1133. doi:10.1039/b101567m

10. Mata, Y.; Diéguez, M.; Pàmies, O.; Claver, C. Adv. Synth. Catal. 2005, 347, 1943-1947. doi:10.1002/adsc.200505192

11. Diéguez, M.; Pàmies, O.; Claver, C. Adv. Synth. Catal. 2005, 347, 1257-1266. doi:10.1002/adsc.200505013

12. Diéguez, M.; Pàmies, O.; Claver, C. J. Organomet. Chem. 2006, 691, 2257-2262. doi:10.1016/j.jorganchem.2005.11.024

13. Khiar, N.; Navas, R.; Fernández, I. Tetrahedron Lett. 2012, 53, 395-398. doi:10.1016/j.tetlet.2011.11.043

14. Gläser, B.; Kunz, H. Synlett 1998, 53-54. doi:10.1055/s-1998-3124

15. Goyard, D.; Telligmann, S. M.; Goux-Henry, C.; Boysen, M. M. K.; Framery, E.; Gueyrard, D.; Vidal, S. Tetrahedron Lett. 2010, 51, 374-377. doi:10.1016/j.tetlet.2009.11.028

16. Kraft, J.; Schmollinger, D.; Maudrich, J.; Ziegler, T. Synthesis 2015, 47, 199-208. doi:10.1055/s-0034-1379473

17. Kraft, J.; Ziegler, T. Carbohydr. Res. 2015, 411, 56-63. doi:10.1016/j.carres.2015.04.009

18. Kaji, E.; Kurimoto, E.; Saiga, R.; Matsuura, A.; Harada, K.; Nishino, T. Heterocycles 2005, 66, 453-468. doi:10.3987/COM-05-S(K)54

19. Nakajima, N.; Matsumoto, M.; Kirihara, M.; Hashimoto, M.; Katoh, T.; Terashima, S. Tetrahedron 1996, 52, 1177-1194. doi:10.1016/0040-4020(95)00975-2

20. Campbell, M. M.; Heffernan, G. D.; Lewis, T. Carbohydr. Res. 1994, 251, 243-250. doi:10.1016/0008-6215(94)84289-2

21. Tatibouët, A.; Lawrence, S.; Rollin, P.; Holman, G. D. Synlett 2004, 1945-1948. doi:10.1055/s-2004-830886

22. Liebeskind, L. S.; Srogl, J. Org. Lett. 2002, 4, 979-981. doi:10.1021/ol0200091

23. Leconte, N.; Pellegatti, L.; Tatibouët, A.; Suzenet, F.; Rollin, P.; Guillaumet, G. Synthesis 2007, 857-864. doi:10.1055/s-2007-965932

24. Silva, S.; Tardy, S.; Routier, S.; Suzenet, F.; Tatibouët, A.; Rauter, A. P.; Rollin, P. Tetrahedron Lett. 2008, 49, 5583-5586. doi:10.1016/j.tetlet.2008.07.023

25. Berionni, G.; Maji, B.; Knochel, P.; Mayr, H. Chem. Sci. 2012, 3, 878-882. doi:10.1039/C2SC00883A

26. Lennox, A. J. J.; Lloyd-Jones, G. C. Chem. Soc. Rev. 2014, 43, 412-443. doi:10.1039/C3CS60197H

27. Sprinz, J.; Kiefer, M.; Helmchen, G.; Reggelin, M.; Huttner, G.; Walter, O.; Zsolnai, L. Tetrahedron Lett. 1994, 35, 1523-1526. doi:10.1016/S0040-4039(00)76748-7

28. Steinhagen, H.; Reggelin, M.; Helmchen, G. Angew. Chem. 1997, 109, 2199-2202. doi:10.1002/ange.19971091921 Angew. Chem. Int. Ed. Engl. 1997, 36, 2108-2110. doi:10.1002/anie.199721081

29. Ramillien, M.; Vanthuyne, N.; Jean, M.; Gherase, D.; Giorgi, M.; Naubron, J.-V.; Piras, P.; Roussel, C. J. Chromatogr. A 2012, 1269, 82-93. doi:10.1016/j.chroma.2012.09.025
30. Hayashi, T.; Yamamoto, A.; Hagihara, T.; Ito, Y. Tetrahedron Lett. 1986, 27, 191-194. doi:10.1016/S0040-4039(00)83974-X

31. von Matt, P.; Llyod-Jones, G. C.; Minidis, A. B. E.; Pfaltz, A.; Macko, L.; Neuburger, M.; Zehnder, M.; Rüegger, H.; Pregosin, P. S. Helv. Chim. Acta 1995, 78, 265-284. doi:10.1002/hlca.19950780202

32. Chelucci, G.; Medici, S.; Saba, A. Tetrahedron: Asymmetry 1997, 8, 3183-3184. doi:10.1016/S0957-4166(97)00425-4

33. Nordström, K.; Macedo, E.; Moberg, C. J. Org. Chem. 1997, 62, 1604-1609. doi:10.1021/jo961490+

\section{License and Terms}

This is an Open Access article under the terms of the Creative Commons Attribution License

(http://creativecommons.org/licenses/by/2.0), which permits unrestricted use, distribution, and reproduction in any medium, provided the original work is properly cited.

The license is subject to the Beilstein Journal of Organic Chemistry terms and conditions: (http://www.beilstein-journals.org/bjoc)

The definitive version of this article is the electronic one which can be found at: doi:10.3762/bjoc. 12.18 